\title{
LA MEDITERRANEDAD EN EL ARTE ESPAÑOL DEL SIGLO XX
}

por

miguel camañas bravo

Centro de Estudios Históricos, C.S.I.C.

RUSSUMEN: Desde comienzos del siglo $\mathrm{xx}$, el Mediterráneo - su herencia, sociedad, cultura y particularismos- ha jugado un papel decisivo en el arte español en cuanto a las definiciones artisticas de "avanzada", la aceptación de nuevos procedimientos y las necesarias naturalizaciones. Así, el largo fenomeno de la mediterraneidad artistica del novecientos ha recibido consideraciones de arte regionalista o periférico, de movimiento concreto (noucentisme) o de simple constante o adjetivación de parte del arte español. Pero nunca se ha podido concretar dicho fenómeno con demasiada precisión. Aqui se trata de exponer algunas de las características y dimensiones más acusadas del tema, incidiendo especialmente en dos de sus momentos más significativos y trascendentes: el del desarrollo del noucentisme catalán y el de repliegue del arte español de la postguerra.

Palabras clave. Arte. Plntura. Escultura. Historia Contemporánea de España. Mediterráneo.

ABSTRACT: Since the beginning of the twentieth century, the heretige, society, culture and peculiarities of the Mediterranean world played a decisive role in the development of Iberian art. It helped define the work of the avantguard, the acceptance of new artistic practices and their necessary naturalization. Although it has never been precisely and concretely studied, the influence of a Mediterranean aura on artistic production in this century has been alternately discussed as a regional and peripheal art, as part of a concrete movement (noucentisme), or as an enduring constant in Spanish art. This paper attempts to analyze some of the salient characteristics of this subject, taking special note of two significant moments: the development of Catalan noucentisme and the inward turning of Spanish art in the post-civil war period.

KEY Worns: Art. Painting. Sculpture. Modern Spain. Mediterranean sea.

Vamos a tratar aquí de un tema complejo, poco definido y con múltiples posibilidades de enfonque, como es el de la influencia del Mediterráneo y su 
cultura en el arte del siglo xx. Un tema tan vasto, lógicamente, necesita de algunas acotaciones y precisiones, por lo que desde ahora conviene que tengamos en cuenta que nos centraremos principalmente en el desarrollo de las artes plásticas españolas $\mathrm{y}$, en especial, la pintura, puesto que - como bien se sabe- - fue en ésta donde se dió la experimentación artística que fue en cabeza prácticamente durante todo este revolucionario siglo artístico.

Trataremos, pues, del significado de lo mediterráneo en el arte español, con lo que pretendemos definir las características y dimensiones de este tema y exponer hasta donde abarca nuestro acercamiento. Las precisiones, en tal sentido, resultan importantes y, por ello mismo, ha de partirse de la comprensión del fenómeno de las vanguardias, puesto que de otro modo en nada se entenderá el peculiar desarrollo del arte avanzado en España y su afán por sincronizarse con lo que se estaba haciendo en Europa; afán, eso sí, que nunca perdió de vista que, en su empeño, debía conservar la idiosincrásia y los caracteres más autóctonos espafioles, ya fueran mediterráneos, meseteños, vascos u otros bien marcados. Y así, el Mediterráneo, sus características y su cultura, como parte muy destacada de una notable herencia, jugaron un relevante papel en las definiciones artísticas de avanzada, en la aceptación de los nuevos procedimientos y en las necesarias naturalizaciones.

Debemos considerar, por otro lado, la gran paradoja que se da en el arte español del siglo Xx; pues si bien algunas de las más célebres figuras del arte universal de esta centuria son españolas (Gaudí, Picasso, Juan Gris, Miró, Dalí, Pablo Gargallo, Julio González, Oscar Domínguez, etc.), éstas trabajaron en ambientes internacionales a los cuales hay que adscribirlas, mientras que en la propia España el arte de avanzada -término que conviene más que el de vanguardia- mantenía un profundo desfase con el arte puntero internacional.

Por otra parte, hay también que reparar en la destacada presencia de la constante mediterránea en los planteamientos generales del arte español del primer tercio del siglo xx y su posterior fortuna, mereciendo especial detenimiento una de sus más importantes manifestaciones, esto es el fenómeno del noucentisme catalán y la pintura mediterránea de sentido nacionalista, de donde en gran parte deriva la vigencia y replanteamientos que tuvieron estos postulados durante la etapa de la dictadura franquista, tema que también abordaremos aquí.

La mediterraneidad en el arte español del siglo $\mathrm{xx}$, pues, la pudiéramos considerar de varias formas. Esto es, en primer lugar, como la influencia del marco geográfico donde se desarrolla una parte muy importante y trascendente del arte español de este siglo; es decir el arte producido en Cataluña, Baleares, Valencia, Murcia y la parte Sur-Este de Andalucía.

En este sentido debiéramos hablar de un arte regionalista -o periféricocon varios focos artísticos de gran notoriedad y muy influyentes, especialmente el catalán -el más emparentado con Europa- y el valenciano -que durante mucho tiempo ha sido considerado, dentro y fuera de España, como definidor de las constantes castizas de la pintura española más alegre y festiva-.. Estos focos han recibido una honda influencia del Mediterráneo en cuanto a sus diferenciadores paisajes, sus tipos populares, sus concepciones

Hispania, LVI/, núm, 192 (1996) 115-134 
culturales, su peculiarísima luz, su alegre cromatismo y su diferencial iluminismo, características después llevadas a procedimientos y experimentaciones más arriesgadas y que se convierten casi la esencia de estos focos, a los cuales definen como escuela diferenciada dentro del ámbito peninsular.

En segundo lugar podríamos considerar tal mediterraneidad como mediterraneísmo, esto es, como algo más concreto y activo o, en otras palabras, como un estilo particular nacido en Cataluña a comienzos del siglo $\mathrm{xx}$, por oposición al estilo anterior, el Modernismo, y con la intención de ser más avanzado o "moderno" que el decadentismo de los propios modernistas. Es el movimiento conocido como Noucentisme - palabra catalana inventada en 1906 por Eugenio d'Ors que contiene un juego de doble significado muy dorsiano, pues tanto alude a la nueva centuria como al novecientos-, al que también se ha llamado "novecentismo" o "movimiento mediterraneísta". Se caracteriza, en líneas generales, por unas fuertes componentes de nacionalismo y una muy acusada mirada hacia el arte clásico, singularizada por la rotundidad casi helenística de sus figuras. En este movimiento, que está en la base del nacionalismo o autoctonía artística catalana, será en el que, por ahora, más nos detendremos.

Y, finalmente, también podríamos considerar la mediterraneidad como constante del arte español y casi como adjetivación, caracterizada en términos artísticos por una temática, luz, cromatismo, expresividad y luminosidad concretas, que aparecen en diferentes artistas y en varios momentos de la historia del arte español de este siglo, especialmente - refiriéndonos a nuestra centuria- en sus comienzos, en la postguerra civil española y en el arte último.

Nunca, sin embargo, se acabará de definir esta mediterraneidad, de ineludible presencia, como constante o como estilo del arte español de nuestro siglo; arte sobre el que, por otra parte, conviene advertir que los estudios, aun preocupados por las síntesis generales aceptables, se encuentran todavía hay que reconocerlo- en mantillas, lo que hace que para analizar temas como el que nos ocupa se cuente como punto de partida con bastente precariedad y apenas planteamientos incipientes.

Con todo, si, remontándonos a los inicios modernizadores, comenzamos por analizar las filiaciones estilísticas que condujeron en España a la apertura al arte vanguardista que se daba en Europa, encontraríamos, como José María Moreno Galván ", que tres fueron los caminos que se dirigieron a la renovación y que, de los tres, participaron los focos españoles más directamente conectados con el tema de la mediterraneidad. Esto es, en primer lugar, un expresionismo de fondo, de búsqueda autóctona; en segundo, un impresionismo de resonancia, es decir, sin teorización, y, finalmente, una serie de adelantados españoles de la modernidad, entre los que se diferencia una línea intenacional, formada en el contacto con el exterior, y una línea doméstica, en profunda vinculación con la tradición española.

1 Introducción a la pintura española actual, Madrid, Publicaciones Españolas, 1960, págs. 23-51. 
En cuanto al primero de los caminos -el expresionismo de raíz autóctona-, digamos que, aunque el academicismo decimonónico siguió actuando y proveyendo de fórmulas, reglas, recetas y soluciones a unos artistas españoles que, en su mayoría, ternáticamente se refugiaron en el halago patriotero, produciendo esencialmente asuntos de historia, folclóricos y costumbristas, para otros artistas más inquietos y dados a la indagación el arte era un eterno problema a resolver. Así, la modernidad, por esta última vía, llegó a España profundizando en una de las grandes constantes del arte español, como era la del realismo y, parejamente, por la búsqueda en las constantes genuinas de la tierra, como lo hizo el noucentisme catalán, hasta cierto punto el sorollismo valenciano, los artistas del País Vasco y, sobre todo, pintores meseterios como José Gutiérrez Solana, quien investigó e interpretó como pocos «la España negra».

Este hecho, tan claro en Solana, también fue visible en otros artistas cuyas obras se han visto próximas a las posturas de la Generación del 98, como Ignacio Zuloaga, Ricardo Baroja, Anselmo Miguel Nieto, Juan Echevarría o Julio Romero de Torres. Es decir, se trataba de un expresionismo de fondo, autóctono, que también supo expresarse lejos de la meseta, como lo hizo -y lo veremos más tarde al hablar del novecentismo mediterraneísta- la obra de Isidre Nonell, Manolo Hugué o Joaquim Sunyer en Cataluña. En tal sentido la posición de los artistas noventayochistas y noucentistas resulta equiparable, pues para lo que unos representaba la tierra de la Meseta para otros lo representaba el Mediterráneo, esto es que, para unos y otros, existía un elemento vertebrador y de identificación que daba la posibilidad de intimar con lo propio y su tradición.

Respecto a la segunda vía de modernización, la del Impresionismo, hay que señalar que este Impresionismo, salvo en el caso del asturiano-madrileño Dario de Regoyos, fue más empírico que doctrinario, más de experimentación. que de teorización. Es decir, fue un impresionismo que se realizó en mayor grado tratando de solucionar problemas luminosos y cromáticos que escuchando a los maestros de París; fue, pues, un impresionismo interno, surgido sobre el terreno al tratar nuestros pintores de solucionar los problemas cromáticos para crear la luz, como por ejemplo ocurrio con el gran precursor que fue Ignacio Pinazo y el investigardor en solitario que fue Francisco Gimeno.

Así pues, el Impresionismo, como se ha entendido en España por la pintura de Joaquín Sorolla o Gonzalo Bilbao, fue en realidad la resolución de problemas lumínicos por medio del color y no, como en Francia, la resolución del problema del espacio aéreo mediante la captación de la luz como vehículo de cromátismo. Este problema de la definición espacial aérea solo lo abordó Regoyos, que incluso practicó el divisionismo y puntillismo, y, en menor medida, Aureliano de Beruete.

Por otro lado, en Cataluña, también se dieron indagaciones sobre el color para conseguir el cromatismo del paisaje mediterráneo en la obra de Joaquim Mir y Hermen Anglada Camarasa, aunque en ellos también son perceptibles los arrastres del próspero estilo modernista catalán.

Hispania, LVI/, núm. 192 (1996) 115-134 
En cualquier caso, entre este especial luminismo valenciano y cromatismo catalán, se encuentre una primera definición de esa característica mediterraneidad que venimos abordando.

Por último, nos falta comentar el camino de los adelantados españoles de la modernidad, con sus líneas internacional y doméstica. Se ha dicho, en cuanto al primer aspecto, que España, en vez de exportar arte, ha exportardo artistas. Pero precisamente esto ha contribuido a la formación de nuestro creadores y, por tanto, en cierto modo, a la apertura de la modernidad española y su intenacionalización.

Ello ha ocurrido con Picasso, Juan Gris, Pablo Gargallo, Julio González, Joan Miró, Salvador Dalí, Oscar Domínguez, etc. Pero por París pasaron también otros artistas, como Vázquez Díaz, María Gutiérrez Blanchard, Pancho Cossío, Benjamín Palencia o Mateo Hernández, que conforman, junto a los artistas antes citados, la llamada Primera Escuela de Paris, la cual ha de distinguirse de la de los artistas que comenzaron a llegar en los años treinta y a los que retuvo alli la nueva situación creada en España por la guerra civil (Francisco Bores, Hernando Viñes, Ismael Gómez de la Serna, Joaquín Peinado, Oscar Domínguez, Antoni Clavé, Luis Fernández, Pedro Flores, Ginés Parra, Manuel Ángeles Ortiz, Emilio Grau Sala, Orlando Pelayo, Apel'les Fenosa, Baltar Lobo, Honorio García Condoy, etc.), conformando la Segunda Escuela de Parts.

Esa Primera Escuela de París es la que conlleva la línea más internacional del arte español y es también la vía por donde entraron notables enseñanzas. Pero no vamos a insistir en sus artistas más notables, porque su actividad incide fuertemente en un ámbito mucho más amplio que el español. No obstante, si hay que señalar que a otros artistas de esta Escuela que regresaron pronto, como Vázquez Díaz y Pancho Cossio o, antes que ellos y en el escenario catalán Hermen Anglada Camarasa y Santiago Rusiñol, debe mucho la formación de los jóvenes artistas españoles del momento.

En cuanto a la línea doméstica de la modernidad española, queda integrada por un arco de artistas que abarcan dos extremos diferentes. Es decir, de un lado, las enseñanzas de varios de aquellos creadores que regresaron a España, como ejemplifica el caso de Daniel Vázquez Díaz (1882-1969), quien volvió a Madrid en 1918 tras doce años en París, sometió entonces su obra a las formas del arte internacional, aunque pasándola por un tamiz muy español, pues tanto aprendió de las lecciones de geometría de Cézanne y el cubismo, como acudió a una genealogía y temática de maestros tan españoles como Zurbarán, quienes habían buscado los arquetipos de la forma. De otro, asimismo la integraban otros característicos representantes, de evolución más personal, como José Gutiérrez Solana (1886-1945), cuyo magisterio entre la juventud también fue importantísimo. Pero el agresivo expresionismo de Solana presenta grandes problemas de adscripción, aunque se trata la suya de una expresividad crítica y de "veta brava" cuya filiación proviene de las "vanitas» barrocas de Valdés Leal, pasando por la obra más desgarrada de Goya, hasta llegar con gran fuerza a nuestro siglo. 
El magisterio de uno y otro ejemplificador pintor, con todo, actuó en franca divergencia, pero ello mismo suponía crear las bases para la dialéctica (forma-expresión) en las que se asentó el arte posterior más destacado, es decir la abstracción informalista. Por otro lado, se podría objetar que los ejemplos aducidos de Vázquez Díaz y Solana, inciden especialmente en una mayor identificación con la Meseta; es cierto, mas algo semejante podríamos decir respecto a la intimación con el Mediterráneo en la obra de Sorolla para la pintura valenciana o en la de Ramón Casas, Isidre Nonell o Joaquim Sunyer para la catalana, y veremos seguidamente como se inscribe su caso, al que ya estamos en posición de poder comparar.

Recordemos, pues, que a finales del siglo xxx surgió en Cataluña, gracias a ciertos condicionantes distintos a los del resto de la Península, una realidad compleja que se llamó Modernismo. Fue un momento en el que la periferia española adquirió un protagonismo artístico del que hasta entonces había carecido, pues venía siendo detentado por Madrid, es decir por la Academia, que había impuesto a Roma como punto estético de referencia, mientras Barcelona y el Modernismo impondrían como modelo a París.

Esta generación modernista que abandonó los dos puntos de referencia tradicionales (Madrid - la Academia-y Roma) por París, dió grandes nombres en el terreno arquitectónico, como Antoni Gaudí, Lluís Domènech i Montaner, Puig i Cadafalch, etc., pero también lo hizo en el campo de las artes plásticas, donde hay que contar con pintores modernistas como Ramón Casas, Santiago Rusiñol, Miguel Utrillo, Joan Llimona, Riquer, Graner, Feliu de Lemos, Lluis Masriera o Sebastià Junyent o escultores como Josep Llimona, Clarasó, Blay o Arnau; artistas que introdujeron en Cataluña un postimpresionismo moderado, que suponía un cambio técnico y temático. En este cambio aparecerían las composiciones desde ángulos inusuales, los tonos matizados y la abundancia de grises - característicos de la pintura modernista del momento- y los contrastes lumínicos; es decir un aprendizaje fundamentalmente parisino que, traspuesto a un escenario diferente -el catalán-, iba a dar lugar a una paleta más clara, al tiempo que la luz mediterránea iba a modificar notablemente las condiciones de luminosidad y sus contrastes, mientras el mismo ambiente suavizaría y redondearía los volúmenes de las esculturas.

En cuanto a Valencia, el otro gran foco de pintura española emparentada con el Mediterráneo, consigue en esta época -en la que en Cataluña dominaba el Modernismo- consolidar un importante papel, casi hegemónico. Sin embargo, la actitud valenciana fue muy diferente a la innovadora mirada catalana que se había inspirado en la modernidad urbana europea, es decir, el tropel de pintores valencianos -muchos de los cuales llegaron a ser tanto o más internacionales que los catalanes- surgió por evolución gradual a partir de los géneros y estilos tradicionales.

Fue, pues, en el cambio de siglo cuando la gran pintura valenciana desarrolló un modo nuevo de pintura a partir del realismo ochocentista rural y costrumbrista. Este tipo de evolución es especialmente evidente en el gran 
pintor valenciano del momento, Joaquín Sorolla (1863-1923), quien sin apartarse de los tópicos de la pintura oficial pasó de la pintura de historia a los temas "sociales" de buen tono y, en los años iniciales de nuestro siglo, incorporó a su realismo un acusado tratamiento luminista -que no impresionista- solucionado con una increible habilidad técnica. Mientras, temáticamente, Sorrolla ahondó en las tradiciones españolas y, especialmente, en el costumbrismo y pintoresquismo mediterráneo. Así, junto con Andalucía, la Valencia y, en general, el Mediterráneo de Sorrolla asumieron desde fuera una de las imágenes más emblemáticas de España.

Lo peor quizá fue el número arrollador de seguidores que originó su obra, especialmente en Valencia, los cuales han perdurado hasta fechas muy recientes. Esta sucesión formó escuela pictórica, la escuela sorollista o «sorollismo» simplemente, que tiene a Sorolla casi como único punto de referencia. La nota más característica de esta escuela es el luminismo, aunque sus artistas a veces también trasparentaron otras aportaciones e influencias, como el intimismo, proveniente de otro maestro valenciano, Ignacio Pinazo (1849-1916), caracterizado por una pintura instantánea e inmediata.

Sin embargo, en cuanto a Valencia, también podríamos recordar a un discípulo directo de Sorolla, Manuel Benedito (1873-1963), no demasiado influido por su maestro y que hizo una pintura realista, más conservadora y académica, de temática costumbrista, representando a un academicismo pintoresquista del Mediterráneo que se prolonga e impone hasta los años cincuenta, aunque al llegar a este momento intentaremos ver también otro tipo de pintura más renovador.

Pero, volviendo sobre la evolución catalana, hay que señalar como a la generación de artistas modernistas sucede otra a la que - a falta de mejor nombre- podríamos llamar, como hace Francesc Fontbona en sus intentos por definirla, postmodernista, la cual floreció en los inicios del siglo XX. Entre sus artistas hay que contar con los pintores Hermen Anglada-Camarasa, Joaquim Mir, Isidre Nonell, Josep María Sert, Ricard Canals, Adrià Gual, Juli Vallmitjana, Ramón Pichot o Mariano Pidelaserra, quienes trasladaron a los suburbios barceloneses los mismos temas que los modernistas, aunque los revistieron de tonalidades más cálidas y manifestaron cierta denuncia social (no en balde se les llamó la Colla de Sant Martí, por el barrio en el que solían trabajar, y la Colla del Safrà -grupo del azafrán-por sus tonalidades), aplicaron nuevas sugerencias lumínicas y emplearon nuevos recursos técnicos, característicos del postimpresionismo y especialmente visibles en el hábil manejo de los matices del color y en el asomo de cierto expresionismo colorístico, que parece apuntar hacía lo que será la pintura fauve francesa.

Por otro lado, desde 1906 comienza a cuajar una nueva generación, la noucentista. El joven Eugenio d'Ors, a partir de esta fecha, había empezado a hablar de la presencia de un nuevo movimiento cultural, al que correspondía una nueva ideología. Lo llamó Noucentisme, incidiendo con ello en el nuevo marco temporal en el que surgía y su novedad frente al resto de los movimientos, provenientes del ochocientos. 
Así, se fue tomando conciencia de la existencia de este nuevo movimiento, que fue configurándose y acumulando contenidos sobre la marcha hasta quedar definido en 1911. De este modo, como dice Fontbona:

«tras una etapa modernista que había representado, en general, un alineamiento del arte español con las corrientes modernas francesas y norteuropeas, lo que el novecentismo significó fue una vuelta al mediterraneísmo y a la tradición autóctona, incluso en ocasiones al puro casticismo" ${ }^{2}$.

El noucentisme, además, asumió específicamente en la cultura catalana, como recuerda Guillermo Díaz Plaja en su ensayo sobre el novecentismo español, «la defensa de la Ciudad frente a la Rusticidad, del Clasicismo frente a la tradición neorromántica de los Juegos Florales; de la tradición mediterránea frente a los modos germanizantes de fin de siglo», pero también hay que entender estos hechos dentro de unas coordenadas y voluntad de conexión internacional más amplias ${ }^{3}$.

Hay, con todo, ciertos rasgos comunes y de época dados por la misma coexistencia y solapamiento, pues, un modernista (como Ramón Casas o Rusiñol) y un noucentista (como Sunyer o Manolo Hugué) son diferenciables, entre otras cosas, por pertenecer a dos generaciones distanciadas, aunque son contemporáneos y, por tanto suceptibles de contemporizar en ciertos aspectos. Más difícil resulta aun la plena distinción de los postmodernistas, quienes a veces fueron asimilados por el Modernismo y otras incorporados al Noucentisme, como hizo d'Ors con Joaquim Mir e Isidre Nonell.

En el proyecto noucentista, por otra parte, se fue perfilando una nueva ideología, que seguía el programa político del partido catalanista entonces hegemónico, la Lliga Regionalista. Se trataba, pues, de una ideología muy clara política y culturalmente, pero muy ambigua en el ámbito de las artes plásticas. El joven D’Ors, desde su "Glosari», la sección periódica que escribía para La Veu de Catalunya, se convirtió en el árbitro de la crítica del momento, pero su actitud respecto a la vanguardia carecía de precisión; pues si, por un lado, pregonaba un retorno a las formas clásicas y a lo catalán, por otro, llamaba a una modernidad entendida tanto a través de Cézanne como del fauvismo y el cubismo francés. Se trataba, con todo, de un retorno a los orígenes, en la línea

\footnotetext{
2 «Del Romanticismo al Novecentismo» en AA.VV.: Colección Banco Hispano Americano, Madrid, Fundación B.H.A., 1991, págs.146-159.

3 Para Díaz Plaja, el novecentismo catalán de hecho participa de las caracteristicas generales del movimiento a nivel nacional, las cuales son la decisión de sustituir el estilo autodidáctico y anarquizante de la generación anterior por un talante sistemático, el esfuerzo por conectar plenamente con la cultura europea y el propósito de realizar una revolución cultural desde los resortes del poder. En el plano ideológico, el novencentismo se caracteriza por la exaltación de los valores universales frente al particularismo nacional y la defensa del clasicismo frente a la tradición neo-romántica; voluntades de las que son exponentes Ortega y Gasset, D’Ors, Ramón y Cajal, Menéndez Pidal, Xirau, Nicolau d'Oliver, Rubió y Balaguer, Marañón, Manuel Gómez Moreno, Pi y Suñer, Serra Hunter, Bosch Gimperá, etc. (Estructura y sentido del Novecentismo español, Madrid, Alianza, 1975, págs.14-15).

Hispania, LVI/, núm. 192 (1996) 115-134
} 
del primitivismo --que tanta importancia había tenido en Europa- - y a través del tratamiento alegórico de los temas y de la mitificación de lo mediterráneo y su tradición. Además, se incorporó la interpretación de la modernidad a través del clasicismo, algo en la tónica de lo que en Europa se conocería como eretorno al orden", con lo que la dualidad primitivismo-clasicismo mantendría enormes diferencias entre los creadores noucentistas, entre quienes tanto aparecerán vanguardistas como el uruguayo Joaquín Torres García, como moderados del tipo del pintor y crítico Rafael Benet.

Con todo, las figuras más paradigmáticas del movimiento noucentista sin duda fueron el pintor Joaquim Sunyer (1874-1956) y el escultor Manolo Hugué (1872-1945). El primero, aunque no había participado en su gestación y mantuvo siempre su caracter independiente, fue su mejor representante en pintura, protagonizando un destacado papel en la plástica catalana tras la muerte de Nonell en 1911. Poco antes de esta fecha comenzó la instalación de Sunyer en su país, tras haber asimilado desde 1896 el postimpresionismo en París y haber aprendido del último Renoir, Cézanne y el primer cubismo. Regresaba con la formula de un estilo diferente, en el cual la concreción de los volúmenes jugaba un papel fundamental y destacaba la importancia que concedía a la simplicidad y primitivismo de las formas. Este nuevo estilo, ade. más, buscaba hacer trascender la significación de los valores clásicos y mediterráneos, destacando así tanto lo alegórico como lo cotidiano de los paisajes y escenas más auténticos y representativos de Cataluña, lo que rápidamente fue asumido por los intelectuales y artistas que buscaban el reencuentro con la tradición catalana.

Manolo Hugué, en este sentido, también fue muy bien acogido por el noucentisme, pues supo crear a su vuelta de París una escultura de formas sencillas y primarias, sólidos volúmenes, búsquedas arcaizantes y temas vinculados a la vida campesina mediterránea, síntesis con la que, a pesar de sus particularidades, entroncaba con el Noucentisme aportándole un cuidado popularismo.

El clasicismo de Manolo Hugué resultó así bastante peculiar. No obstante, el Noucentisme consiguió que la escultura -mejor fuente de búsqueda de mitos clásicos que la pintura-gozara de cierto protagonismo y que el clasicismo fuera muy evidente ${ }^{4}$, como claramente se detecta en otro importante escultor noucentista, Enric Casanovas, en cuya escultura abundan las referencias a lo griego y al helenismo, pero superando este historicismo con cierta tendencia al primitivismo y al simbolismo lírico e íntimo.

Con todo, debemos considerar que, aparte de los artistas más cercanos al Noucentisme, son muchos los creadores que podemos asociar a este movimiento, puesto que entre 1906 y 1936, como ha señalado Eugenio Carmona, "el noucentisme fue el cuerpo de la cultura catalana" y el hecho resulta de

4 Véase D'ORS FüHRER, Carlos: «Apuntes sobre la escultura noucentista», Espacio, Tiempo y Forma, núm. 2, Madrid, UNED, 1988, págs. 333-354 y BAZÁN DE HUERTA, Moisés: «Observaciones sobre el clasicismo en la escultura española contemporánea (1900-1936)" en AA.VV: Actas del X Congreso del CEHA. Los clasicismos en el arte español, Madrid, UNED, 1994, págs. 105-112.

Hispania, LVI/, núm. 192 (1996) 115-134 
gran importancia porque buena parte del arte más renovador español «provino de Cataluña y todo arte catalán de estos años, casi forzosamente, mantuvo algún tipo de relación con el noucentisme", ya que la dimensión que alcanzó «excedió los ámbitos de lo específicamente artístico o literarion ${ }^{5}$.

Fueron pocos, pues, los artistas catalanes que escaparon a la influencia noucentista, ya que fueron varias sus dimensiones de actuacion. Las cuales, como indica el mismo Carmona, podrían ser resumidas a tres. Es decir, en primer lugar, una dimensión política, esto es la del nacionalismo catalán, muy cercana a los presupuestos catalanistas de Enric Prat de la Riba. El propio D'Ors afirmó que la política de Prat era la política de los noucentistas y el político premí́ a D'Ors haciendo del noucentisme el arte oficial del nacionalismo catalán. En segundo lugar podemos considerar una dimensión estética, a saber, la del clasicicismo mediterraneísta. En este sentido, el clasicismo dorsiano se basaba en una visión idealizada del Mare Nostrum y en la identidad cultural entre Cataluña y el Mediterráneo, algo que se afirmaba colectivamente y que agradaba a la burguesía catalana que sostenía la política de Prat de la Riba. El que este arte de voluntad clasicista y mediterránea se promoviera como arte del nacionalismo catalán era así algo fácilmente aceptable. Finalmente, como última dimensión, hallaríamos una voluntad de acción social y cultural que se concretaría en la "obra civilista" dorsiana, que en definitiva suponía la puesta en práctica de las otras dos dimensiones 6 .

Estos planteamientos, con todo, solo valdrían para Cataluña, pero en cuanto al panorama general del conjunto del suelo peninsular, en este primer tercio de siglo, hay que tener también en cuenta que la renovación artística que intentaba vincularse a Europa pasó por dos momentos diferentes. Uno entre mediados de la década de 1910 y mediados de la de 1920. Fue un momento inicial y pionero en el que simultáneamente coincidieron las vanguardias que se habían desarrollado y venían desarrollándose en Europa con la mesura y clasicismo del llamado "retorno al orden» característico del período de entreguerras. El segundo momento se dio entre 1925 y 1936 y fue el período de introducción y extensión de los anhelos de enlace con el vanguardismo internacional, en el que el clasicismo del «retorno al orden» aparejó cierta síntesis de tradición y vanguardia.

La bisagra entre uno y otro momento fue la celebración en Madrid, precisamente en 1925, de la I Exposición de la Sociedad de Artistas Ibéricos. Fue el primer indicio institucional y colectivo de que la modernidad estaba cuajando. Lo más interesante de esta Exposición, celebrada en el Palacio de Exposiciones del Retiro, fue, pues, la revelación de jóvenes nombres, entre otros Francisco Bores, Salvador Dalí, Benjamín Palencia, Ángel Ferrant, Alberto Sánchez, Santiago Pelegrin, José Moreno Villa, Rafael Barradas, José Bernal, Antonio Rodríguez Luna, Santiago Ontañón, Ramón Gaya, Ponce de

5 Picasso, Miro, Dali y los orígenes del arte contemporáneo en España, 1900-1936, Madrid, MNCA Reina Sofia, 1991, pág.17.

6 Ibidem, págs.17-18.

Hispania, LVI/, num. 192 (1996) 115-134 
León, Arturo Souto, José Frau, Maruja Mallo, Maroto, Juan Manuel Díaz Caneja, etc., junto a algunos maestros como Solana o el uruguayo Joaquín Torres-Carcía. Pero, en definitiva, fue una importante toma de conciencia conjunta sobre la modernidad, aunque contenía dos visiones diferentes sobre su concepción y el modo de actuación, que fueron las que se siguieron en los dos núcleos artísticos más importantes de la península. Es decir, por un lado, surgió la aspiración de estar al día en cuanto a problemática artística, afán antepuesto por el grupo catalán en sus futuras investigaciones; por otro, se instaló la idea de que en lo auténtico español había una parte imperecedera de modernidad, lo cual cuajó más entre los grupos centrales. Por otro lado, consecuentes con una de estas visiones, otros artistas sintieron la necesidad de emigrar a París o de acercarse a la tradición de España.

La Exposición de Artistas Ibéricos se convierte así en un hito del arte espanol, en el cual despierta la concienciación de modernidad, por lo que no es de extrañar que a veces se haya hablado de la "generación del 25 " --en paralelo a la literaria del 27- para designar al grupo de artistas plásticos que obtienen ahora su reválida. Pero la Exposición de 1925, además de concienciar y dotar de alas a los más jóvenes, resulta también importante porque dió carta de naturaleza en España a muchas posiciones ya mantenidas y que confluyeron aquí, especialmente dos muy interesantes, el cubismo y el surrealismo.

La actividad renovadora que prosperó en España entre 1925 y 1936 tuvo, pues, dos centros artísticos importantes, aunque de diferente dirección: Madrid y Barcelona.

El arte que se desarrolló en la meseta castellana se mantenía muy unido a la tierra de donde nacía y el género donde mejor se expresó fue el paisaje y sus referencias, como ocurría, entre otros, con Benjamín Palencia, Alberto Sánchez, Antonio Rodríguez Luna y Ángel Ferrant. Hacia 1927 estos artistas se movilizaron buscando una unidad de paisaje y expresión semejante: $\mathrm{El}$ mito del páramo descarnado, la tierra arada, el montículo calcinado por el sol, etc. Había también en ello búsquedas cubistas y surrealistas. De este modo estos artistas, entre los que figuraban los anteriormente citados y otros que pronto se unieron -Rafael Alberti, Ramón Gaya, Juan Manuel Díaz Caneja, Maruja Mallo, Luis Castellanos, Luis Felipe Vivanco, etc. - crearon la Escuela de Vallecas, que cimentó la investigación sobre el paisaje, género que también cultivaron Francisco Arias, Godofredo Ortega Muñoz, Joaquín Vaquero, etc. y que tuvo una importante y larga vigencia, que continuó durante la postguerra, pues la Escuela de Vallecas fue recreada entre 1939 y 1942 por Benjamín Palencia y un grupo de jóvenes artistas, entre los que figuraban Carlos Pascual de Lara, Álvaro Delgado, Francisco San José y otros, quienes continuaron las indagaciones sobre el paisaje y definieron en buena medida el quehacer artístico renovador del período de la autarquía en la capital española y su área de influencia.

Por otro lado, Cataluña, el otro importante centro artístico español, se acercó aún más a Europa. Adoptó el cromatismo impresionista cuando el impresionismo ya estaba superado e innovó con este medio en cierta dirección hacia el fauvismo; al igual que paralelamente experimentó con las enseñanzas de Cézanne y el cubismo encaminándose hacia la creación de una 
nueva concepción de la volumetría. Pero en todo este proceso, del que participaron Joaquim Mir, Josep Mompou, Mallol Suazo, Amat, Mercadé, etc., es perceptible la huella de la mediterraneidad aprendida del noucentisme.

Es decir, en este arte catalán de intención renovadora nuevamente hay que considerar la constante del Mediterráneo, que viene a ser lo mismo que la Meseta para la tierra castellana. Esta mediterraneidad, además de la investigación cromática, impuso a la pintura catalana cierto equilibrado clasicismo y preocupación por la forma y los volúmenes.

Por otra parte, también fue característico de lo mediterráneo su capacidad onírica y surreal, tendencia evocativa y de grandes recursos imaginativos de la que salió la pintura elemental y abierta de Joan Miró y la construida y cerrada de Salvador Dalí.

Posteriormente, la guerra civil no paralizó completamente la actividad artística, aunque si la fue inscribiendo dentro de unas exigencias extra-artísticas y una politización creciente, al rechazarse los planteamientos "neutrales», «objetivos" o "apolíticos» en favor del arte "de tendencia» y "de propaganda». Se hizo así muy marcada la influencia del nuevo realismo de Grosz y los dibujantes y grabadores centroeuropeos.

Entre lo más importante que se desarrolló en este período sin duda estuvo el cartelismo, que conocío un vigor que sólo tenía precedentes parecidos en el cartelismo modernista catalán. No obstante, como ejemplo y quitaesencia de la producción artística de este momento de guerra, podríamos recordar la obra expuesta en el Pabellón Español de la Exposición Internacional de París de 1937, edificio de Sert y Lacasa en el que se expuso La Montserrat de Julio González, El Guernica de Picasso, la Fuente de mercurio de Calder, El payés catalán en revolución de Miró, la colosal escultura de Alberto Sánchez El pueblo español tiene un camino que conduce a una estrella y tantas otras obras ?. La creación catalana, incluso en estos momentos, deja reconocer el sello mediterráneo, ahora matizado por el período de violencia, en una vanguardia que asume cierto realismo militante, que llega hasta La Montserrat de González o el Payés de Miró.

El exilio formó parte también del futuro de muchos de estos artistas. Los dos centros más importantes del exilio fueron Francia y México. El primer país era un lugar de formación tradicional para el artista español, pero las cirunstancias políticas hicieron ahora que en numerosos casos apenas sirviera de destino transitorio. En América los artistas españoles se instalaron en Nueva York, las Antillas, Argentina, etc., pero el centro que más recibió, sin duda, fue México, que, por otra parte, contribuyó a que entre los artistas allí llegados se desarrollara notablemente la influencia del realismo socialista, si bien tanto entre valencianos como catalanes, siguió pesando la formación y recuerdo del Mediterráneo, a lo que contribuyeron sus propias casas regionales y asociaciones, e incluso sus mismas publicaciones en catalán, como Pont Blau.

7 Sobre el Pabellón véase ALıX TRUEBa, J.: «E] Pabellón Español en la Exposición Internacional de Paris, 1937\%, en el catalogo Pabellon Español; Exposición Internacional de París, 1937, Madrid, Centro de Arte Reina Sofia, Junio-Sep.1987, págs. 6-171.

Hispania, LVT/, núm. 192 (1996) 115-134 
En cuanto a España, la historia es conocida. No cuajó un arte franquista con base teórica al modo del fascista en Italia o del nazi en Alemania. Los esbozos de una teoría franquista del arte, por otra parte, estuvieron siempre llenos de paradojas y contradicciones, aunque el distintivo de la catolicidad y el ideal de la España hegemónica del Siglo de Oro, encamidados por la vía del realismo clasicista tendente a lo mítico y a lo simbólico y con oscilaciones entre la simplicidad mística y el ritual fastuoso, estuvieron detrás de sus intenciones de formulación.

Mas lo que ocurrió durante la postguerra fue, en la práctica, que el academicismo más retardatario y conservador tomó la delantera en las intenciones de hacer un arte representativo de los vencedores del conflicto bélico. Este academicismo repartio premios y prevendas hasta el golpe de mano que se intentó dar, precisamente desde lo oficial, con la convocatoria de la I Bienal Hispanoamericana de Arte en 1951, acontecimiento de donde arranca la normalización de la situación del arte vanguardista español y el comienzo de su sincronización con la escena artística internacional, lo cual se fue produciendo durante los años cincuenta gracias a la fórmula del arte informalista.

No obstante, en la década de la autarquía, además del omnipresente sorollismo valenciano, que con frecuencia se ofreció desde lo oficial como modelo o propuesta de formación para los artistas jóvenes, siendo del tipo de pintura premiable por los academicistas jurados de las Exposiciones Nacionales de Bellas Artes, hubo otros intentos modernizadores ligados o comprometidos con el Mediterráneo y que en cierto modo recogieron la vieja antorcha de la investigación -por lo demás, nunca perdida - que veímos aparecer a comienzos de siglo con el noucentisme.

Así pues, podrían citarse, con el Mediterráneo como centro o parte esencial del hecho creativo, diferentes ejemplos en ambos sentidos expuestos, esto es la vía del academicismo y la vía de la investigación. Acaso hubo en la potenciación de la orientación clásico-medierránea cierta influencia del novecentismo italiano, como ha destacado Francisco Calvo Serraller ${ }^{8}$, pero lo cierto es que estaba detrás la poderosa tradición catalana y valenciana.

De este modo, como plasmación de estos nuevos contenidos, podríamos recordar como tras la guerra civil, el régimen triunfante celebraba en el Museo de Arte Moderno de Madrid, entre Febrero y Marzo de 1940, una Exposición del dibujo, acuarela y grabado Mediterráneo, 1839-1939, patrocinada, como se hacía constar en el catálogo, "por el Estado" y «organizada por las Jefaturas

${ }^{8}$ Según el mismo, durante estos años cabe observar «el intento de promocionar una orientación vanguardista de naturaleza "clásico-mediterránea» al estilo del novecentismo italiano». Los mismos intelectuales falangistas de vanguardia «propiciaron esta reivindicación del espíritu clásico-mediterráneo» y su «mediterraneísmo solar, clasicista e imperial, propuesto como regeneración de la vanguardia» ilustraría «el porqué del interés por el arte italiano durante estos años de la posguerra, cuyo hito principal fue la exposición de arte italiano contemporáneo que tuvo lugar en Madrid en 1948), ("iAislamiento internacional o vacio social? Reflexiones sobre el arte español de la década de los cuarenta a través de las exposiciones" en AA.VV: Arte para después de una guerra, Madrid, Sala Plaza de España de la Comunidad de Madrid, Dic.1993-Enero 1994, págs. 69-75). 
Provinciales de Falange Española Tradicionalista y de las JONS de Madrid y Valencian. Presentaba después una legión de artistas catalanes y valencianos de este siglo, acompañados de algunos del siglo pasado y otros a caballo entre ambas centurias, como Mariano Fortuny (1839-1874), Antonio Gisbert (18351902), Ramón Martí Alsina (1826-1894), Francisco Domingo (1842-1920), Ignacio Pinazo (1849-1916), Emilio Sala (1850-1910), José Belliure (18551937), Francisco Gimeno (1858-1927), Cecilio Pla (1860-1932), Sorolla (18631923), José Llimona (1864-1934), Ramón Casas (1866-1932), Joaquirm Mir (1873-1940), José Navarro (1867-1923), Xavier Nogués (1874-1941), Isidro Nonell (1873-1911), Manuel Benedito (1874-1963), Ricardo Canals (18761931), José Clará (1878-1958), Juan Colom (1879-1970), Ricard Opisso (18801966), Salvador Tuset (1883), José Capuz (1884-1964), José Segrelles (1885), Domingo Carles (1888-1960), Juan Bautista Porcar (1889), José de Togores (1893-1970), Josep Obiols (1894), Antonio Vila Arrufat (1894), Rafael Llimona (1896-1934), Juan Commelerán (1899), Miquel Villà (1901), Pere Pruna (19041977), Genaro Lahuerta (1905-1985), José María Mallol Suazo (1910), Francisco Lozano (1912), José Amérigo (1915), etc ${ }^{9}$. Pero más interesantes resultan las palabras sobre el arte y la política que el ministro Rafael Sánchez Mazas pronunció con motivo de su inauguración, en las que señalaba:

«No olvidéis que nuestra pintura mediterránea es una pintura cara al sol, cara al mar azul por donde nos vinieron las ideas solares de Jonia y de la Magna Grecia, las ideas exactas e imperiales, que todavia hoy siguen sosteniendo a la pequeña Europa en el dominio universal de las gentes, por obra de la técnica, el arte, la razón y la política. Aún en los peores momentos habéis querido captar en la luz limpia y en la línea pura cosas universales y simbólicas. Y para final, una cosa os digo: que ganaréis victorias en los lienzos si pintáis según las ideas y métodos que han ganado victoria en el campo de batalla, si servís al orden total con un ritmo de oro. Ahora el Estado como nunca puede deciros: 'En la lucha por el orden patrio, yo soy vuestro hermano mayor" "10

En cierto modo, tales palabras representaban una especie de declaración de intenciones sobre la pintura que se pensaba apoyar y la fuerte presencia que en la Nueva Espania tendría el tema del Mediterráneo y su luminismo pictórico, convertido ahora en un verdadero academicismo, pues portaba ya muy poca dosis de innovación. Por otro lado, temáticamente - y eso interesaba al nuevo régimen- se emparentaba con lo más castizo de la tradición española, mientras en cuanto a lo técnico, aunque modo ya consolidado, ofrecía ciertos visos de modernidad que, en el conjunto, desde fuera, eran asumidos junto a lo temático como una de las imágenes más quintaesenciadas y simbólicas de lo español.

9 Exposición del Dibujo, Acuarela y Grabado Mediterráneo, 1839-1939, Valencia, Impr. La Semana Gráfica, Noviembre 1939.

10 SÁNCHEz MAZA, R.: «Confesión a los pintores», Arriba, Madrid, 17-III-1940, también en R.S.M.: «Textos para una política de arte», Escorial, T.IX, núrr. 24, Madrid, Octubre 1942.

Hispania, LVI/, núm. 192 (1996) 115-134 
Tal dirección, aunque contó con un destacado impulso institucional, no necesitó siempre resumirse a la iniciativa oficial, puesto que tenía un gran número de partidarios. Así, por ejemplo, entre abril y mayo de ese mismo año de 1940, se presentó en la sala Syra de Barcelona el primer salón de un grupo de artistas, saludado favorablemente por las entidades oficiales y el Museo barcelonés, que se autodenominó Promoción Mediterránea de Artistas Pintores y Escultores. El grupo, que reunía a pintores como A. Olivé Marsá, Jacinto Olivé, Alfredo Opisso y F. Serra y escultores como A. Ramón González y F. Juventny, buscaba un objetivismo mediterráneo de reminiscencias renacentistas, como se señaló en su presentación, donde se dijo:

«Hoy, al reanudarse las actividades artísticas de alcance social se presentan unidos algunos pintores y escultores bajo el título de "Promoción mediterránea». Bello es el gesto: semeja que el nuevo grupo..., escudándose contra el vaivén de las tendencias y queriendo actuar con cordura se ha llamado "Mediterráneo", con el afán de confusión de las características de sus varios componentes, a beneficio de aquel objetivismo tan propio de nuestro mar y nuestro clima que no mitiga la pasión y que si patronazgos deseara nosotros propondríamos el de Doménico Ghirlandajo para los pintores y Andrea Verrocchio para los imagineros; estilo el de ambos artista: sensible, detallado, metálico" ".

Pero aparte de la organización de estas muestras, también aparecieron durante esta década de los cuarenta otros grupos de artistas y otras acciones que se acercaron a las constantes mediterráneas con intenciones más innovadoras, siendo, en realidad, lo que hizo más interesante el núcleo artístico catalán de la primera postguerra. Podemos recordar así, entre la actuacion integradora y recuperadora, la creación del grupo Els Vuit y la revista Ariel, ambos nacidos en la Barcelona de 1946.

Els Vuit (los ocho), fue un grupo compuesto por los pintores Albert Ràfols Casamada, María Girona, Ricardo Lorenzo, Vicenç Rosell, Joan Palà, el escultor Miguel Gusils, el poeta Jordi Sarsanedas y el músico Joan Comellas. Tuvo un sentido divulgativo de la vanguardia artística y de integración de las artes, siempre con ciertos toques culturales - homenajes a Ravel, Valle Inclán, García Lorca- que quedaron reflejados en sus exposiciones.

Diferente carácter tuvo Ariel, revista dirigida por Josep Palau que dió cohesión a un interesante y activo grupo de artistas e intelectuales interesados por la cultura catalana contemporánea. Publicada íntegramente en catalán, su primer número apareció en mayo de 1946, continuändo su edición hasta 1951. El espíritu de la publicación, en la que colaboraron numerosos poetas, críticos y artistas catalanes, era el catalanismo conservador y la postura estética especialmente intentaba reentroncar con el noucentisme, lo que suponían sacar a la luz el estímulo y la vía de enlace con la modernidad de anteguerra,

11 Rafols, J. F.: «Presentación de la exposición del Primer Salón Galería Syra. Promoción Mediterránea de Artistas", (Recogido por BarRoso, Julia: Grupos de pintura y grabado en España. 1939-1969, Oviedo, Universidad de Oviedo, 1979, págs. 28-29). 
estando siempre muy presentes en su actividad la cultura mediterránea como base de su estética y como dirección investigadora.

Pero las búsquedas en la tradición cultural mediterránea no sólo se dieron en los grandes focos artísticos catalán y valenciano, sino que también en la Andalucía suroriental apareció el Mediterráneo como base de una estética apadrinada por Eugenio d'Ors. Nos referimos a la configuración en Almería, desde los primeros años de la década del llamado Grupo Indaliano, que toma el nombre del patrón de la ciudad, san Indalecio. Las bases del grupo parecen estar puestas en 1946 y, capitaneado por Jesús de Perceval, su fundador, con cierto apoyo oficial y el pronto beneplácito de los gustos del resurgir clasicista de D'Ors -quien los presentó en 1947 en el Museo de Arte Moderno y en 1948 en el VI Salón de los Once--, se orientaron siempre hacia la recuperación de una tradición fundamentalmente mediterránea ${ }^{12}$. Así, el grupo llegó a estar integrado, entre otros, por Perceval, Francisco Capuleto, Fernando Castellón, Miguel Cantón Checa, Luis Cañadas, Gómez Abad, Enrique Suárez, Antonio López Díaz, Miguel Rueda, Garzolini, José Tola, Anchoniz, Fernández Piñar, Francisco Alcaraz, Juan Antonio Criado, Luis Úbeda y Juan Cuadrado y en su planteamiento estético, basado en el resurgimiento de la cultura mediterránea, se combinaron desde elementos del clasicismo renacentista hasta elementos del surrealismo en voluntad de entroncar con la cultura del Algar y el vaso campaniforme; eclecticismo para el que, junto a la proposición de indigenismo, mezclaron toda una serie de actitudes entre lo formal y la pintura de fuerte expresionismo dramático, siendo frecuente la carga literaria, las visiones colosales y las escenas épicas.

Fue importante también, como preparación del interesante surgimiento de grupos en la década de los cincuenta, el nacimiento en Valencia, en 1947, del Grupo $Z$ y el Grupo 2, que tuvieron algunos componentes comunes como José Vento, Manolo Gil, Federico Montañana, Jacinta Gil, Manuel Benet, Xavier Oriach, etc. Ambos tuvieron una vida en torno a los dos años, durante la cual pretendieron acabar con el sorollismo adocenado que todavía se practicaba en Valencia y tomar conciencia de la realidad artística del momento, siendo un precedente para el futuro grupo abstracto Parpalló (1956-1961), en el que figuraron algunos de los miembros y objetivos ya apuntados por estos grupos.

Con todo, sin duda el núcleo artístico más interesante y avanzado relacionado con el Mediterráneo siguió siendo Barcelona, donde en 1948 se creó uno de los grupos de intención vanguardista más interesantes de la postguerra, es decir el grupo Dau al Set, integrado por los pintores Antoni Tàpies, Modest

12 El propio Perceval, en 1951, a raíz de una interesante polémica decía, respecto a la vinculación del grupo con la tradición y el apoyo oficial recibido, que los indalianos eran «de apostólica actitud tradicional y renacentista plástica; patrocinados por la Falange de Almería. La Primera Exposición Indaliana la inaugura nuestro Caudillo en su viaje triunfal por Andalucia y sus exhibiciones en Madrid las patrocina la Secretaria General del Movimiento. Las Exposiciones las inaugura el señor Ibáfiez Martín y toman parte el gobernador y autoridades almerienses, y Eugenio d'Ors es indaliano de honor. $\iota$ Quiénes son, pues, esos anónimos defensores de la tradición?w; (Jesús de PeRCEVal: «Quiénes son quien. Perceval en nombre de los indalianos», Pueblo, Madrid, 13-11-51).

Hispania, LVU/, nu்m. 192 (1996) 115-134 
Cuixart, Joan Josep Tharrats, Joan Ponç y los escritores Arnau Puig, Joan Brossa y Juan Eduardo Cirlot. Su actitud supuso un engarce con los brotes vanguardistas de anteguerra, especialmente con el surrealismo. Practicaban por entonces, con algunos elementos cercanos al dadaísmo, una especie de surrealismo magicista y onírico de inspiración en la tradición mediterránea.

Antes de acabar la década también se registra en Barcelona la formación de otros grupos importantes y con fuerte influencia del Mediterráneo. Entre ellos el grupo LAIS, constituído en el Real Círculo Artístico en noviembre de 1949 y que tuvo corta vigencia (se disuelve a finales de 1951). Estuvo integrado por los pintores Ramont Rogent, José Hurtuna, Manuel Capdevilla, Santi Surós, Enric Planasdurà, María Jesús de Solá, Antoni Estradera, M. Surroca y el escultor Francesc Xavier Modolell, quienes expresaron sus inquietudes con la firma de un "Manifiesto Negro", donde atacaban el arte oficial y exponían las carencias con las que se encontraba el artista. Aunque acogidos con gran interés por determinados sectores sociales, su estética no fue semejante en todos y su actitud de compromiso hacia la vanguardia buscó equilibrio y moderación; así, salvo la rica etapa de abstracción geométrica de Planasdurà, el resto se movió en posiciones entre el expresionismo de «veta brava", el fauvismo y el mediterraneísmo.

Es importante destacar también la acción de los grupos barceloneses Cobalto (1947-1949), Cobalto 49 y Club 49, que integrados por críticos, historiadores, escritores, intelectuales y artistas, publicaron su propia revista, intentaron engarzar con los presupuetos renovadores de anteguerra y patrocinaron una importante actividad artística orientada hacia la promoción de los jóvenes artistas catalanes de vanguardia.

En 1950 ya, continuando con la constante floración de grupos artísticos que caracteriza al ambiente catalán de los años cuarenta y primeros cincuenta ${ }^{13}$, hacen su aparición el Grupo Postectura, el Grupo Gerona, el Grupo Inter Nos y el Grupo Indika.

El primero, opuesto a las tendencias subconscientes derivadas de Dada y encaminado hacia un nuevo humanismo desde las tendencias constructivas,

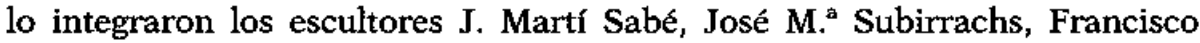
Torres Monsó y los pintores Esther Boix, Ricardo Creus y Joaquín Datzira. El segundo grupo estuvo compuesto en sus comienzos por los pintores gerundenses Joaquín Casellas, Enrique Marqués y Emilia Xargay, que practicaban un arte de fuerte subjetivismo tendente a la abstracción que dieron a conocer en el II Ciclo de Arte Experimental. El Grupo Inter Nos lo formaron hasta 1954 los artistas Hernández Pijuán, Eduardo Alcoy, Llopart, Enrique Sordo y García Estraqués, los cuales editaron una revista combativa a ciclostil, reclamaron cierto independentismo artístico y contribuyeron a la defensa de la abstracción. Finalmente, el grupo Indika de Gerona, que intentó integrar a artistas de las distintas comarcas gerundenses, lo compusieron Joan Masse-

13 Véase el análisis del becho de LAZARILLo (seudónimo de Rafael Santos Torroella): «Más arte que literatura», Correo Literario núm. 15, Madrid, 1-11-1951, pág.7. 
net, Evarist Vallés Rovira, Mariano Oliveras, Bartolomé Massot, Joaquín Casellas, Esther Boix y Emilia Xargay, a los que luego se unieron Jordi Curós, Torres Monsó, Fita y Sibecas, siendo todos ellos defensores de la plástica surrealista y la vinculación de la estética a su tierra natal.

Una prosperidad parecida a la habida en los años cuarenta en cuanto al nacimiento de nuevos grupos y presupuestos artísticos, continuó durante la década de los cincuenta por todo el litoral mediterráneo, hasta alcanzar a los años setenta. Podríamos citar así a los grupos Delta 51, creado en Tortosa por los pintores expresionistas Roberto Escoda, Pallarés-Llé y Jorge Huguet con el fin de dar a conocer el arte actual de su entorno e informar sobre el internacional; Tahull, constituído en 1954 por los pintores Marc Aleu, Josep Guinovar, Jordi Mercadé, Jaume Muxart, Antoni Tàpies, Modest Cuixart y Joan Josep Tharrats con el fin de impulsar la actividad y compromiso artísico renovador del momento; Silex, formado en 1955 por Eduardo Alcoi, Joan Hernández Pijoan, Carles Planell, J.M. Rovira Brull y Lluís Terricabras, quienes, aunque sin imponer filiaciones estéticas concretas, insistieron en conectar su arte con el primitivismo, el simbolismo gráfico, el expresionismo y la abstracción informalista; Cadmio, que se dió a conocer en Barcelona en 1956 y tuvo un gran número de miembros; Gallot, de Sabadell, que quedó constituído hacia 1960 por los informalistas Antoni Angle, Llorenç Balsach, Joan Josep Bermúdez, Alfons Borrell, Manuel Duque, Josep Lloréns, Joaquim Monserrat y Lluís Vila Plana, quienes defendieron en su planteamiento plástico, basado en la action painting pollockiana, el gesto, la acción y la creación colectiva, saliendo en ocasiones a la calle con especies de happenings; Grupo 4, nacido en Barcelona en 1960 y compuesto por Francisco Tersol, Francisco FerrerVives, Francisco Lozano y el escritor Serrano, quienes se enfrentaron al academicismo de lo abstracto; Síntesis, formado por Teo Asensio, Carlos Mensa y Enrique Maas, cuyas actividades se desarrollaron entre 1961 y 1963 unidos en su interés por el informalismo; etc.

Muy interesantes fueron también los grupos aparecidos en Valencia, especialmente Los Siete (1950-1954), grupo nacido de la Escuela de Bellas Artes valenciana con afán de fomento de la actividad artística e integrado por Masiá Sellés, Vicente Castellano, Juan Genovés, Vicente Gómez García, Lloréns Riera, Fillol Roig y R. Hueso, a los que más tarde se unieron Michavila, Ángeles Ballester y Eusebio Sempere; Parpalló (1956-1961), fundado en el Instituto Iberoamericano de Valencia por Agustín Albalat, Manuel Gil, José Marcelo Benedito, Amadeo Gabino, Juan Ribera Berenguer, Salvador Soria, Vicente Castellano, José Martínez Peris, Juan Genovés, Jacinta Gil, Víctor Manuel Giménez, Joaquín Michavila, Salvador Montesa, Vicente Pastor, Francisco Pérez Pizarro, Luis Prades, José Esteve Edo, Nassio y Vicente Aguilera Cerni -a los que más tarde también se unió Monjalés, Andreu Alfaro, Eusebio Sempere, José María Labra, Doro Balaguer, Antonio Giménez Pericas y los arquitectos Estellés y Navarro-, que editó la revista Arte Vivo y se orientó en un principio, ante la heterogeneidad de sus miembros, hacia proporcionar información sobre las tendencias contemporáneas y su propia promoción, para ir 
configurándose después como un activo grupo de vanguardia decantado hacia la abstracción y promotor de numerosas actividades artísticas; el grupo Rotgle Obert (1958), heterogéneo colectivo de talante antiacadémico en el que cabían figurativos como Mestres y Marco Molés, abstractos como Pura Ribes, Salomón y G. Borillo y otras posiciones como las de Bot, Navarro Ferrero, Huguet, Hernández Calatayud, Saval y Albors; etc.; así como, más tarde, el Equipo Crónica (1964-1881), el Equipo Realidad (1966-1977), el Grup d'Elx (1966-1975), de Elche, y otros interesantes grupos que se fueron acercando a lo social.

Asimismo en las islas Baleares surgieron muchos grupos, bastante de ellos integrados por extranjeros, como los grupos lbiza, y otros de más diverso carácter, como los grupos Tago (1959-1961), Teix (1963) y Menorca (1963). Y al sur de la costa mediterránea, a finales de los años cincuenta, apareció en Málaga el activo Grupo Picasso, en el que existieron destacados deseos de promoción de sus miembros (Gabriel Alberka, José Guevara Castro, Enrique Brickmann, Eugenio Chicano, Lindell, Montero, Hernández, Rodrigo Vivar, Owe Pellsjö y Stephan von Reiswitz).

A todos estos grupos, de una manera u otra, les influyó el Mediterráneo, su tradición cultural y artística, su paisaje y su luz, su forma de entender el color y la forma, sus gentes y su actualidad, lo cual les llevó a mantener unos presupuestos agrupadores diferentes en cada caso, pero acordes con este registro mediterraneísta y la situación cultural del momento. Es por ello que no podemos terminar este rápido recorrido por la mediterraneidad que baña al arte español de nuestro siglo sin hablar de una importante asociación que agrupó bajo el signo del Mediterráneo, a partir de finales de los años cincuenta, a algunas de estas inciativas que hemos comentado, demostrando nuevamente la honda trascendencia del medio mediterráneo en la definición del arte avanzado de este momento.

Me refiero con esto al llamado Movimiento Artístico del Mediterráneo, surgido en 1958 y cuya principal función consistió en la organización -en estrecha colaboración con la Asociación de Artistas Actuales de Barcelona, nacida en 1956- de las llamadas exposiciones de "Arte Actual del Mediterráneo», los «Ciclos de Arte Actual del Mediterráneon y diversas muestras en el extranjero. Así, en 1958 este Movimiento presentó en Valencia la «I Exposición de Arte Actual del Mediterráneon, muestra que incluyó a artistas de los grupos Parpalló, Rotgle Obert, Equipo Forma, Los Indalianos, Ibiza, etc. y otros creadores independientes del litoral mediterráneo y que fue luego presentada en Lérida, Alicante, Málaga, Santander, Tortosa y Castellón. Estas exposiciones se fueron repitiendo anualmente, celebrándose cada año en una ciudad mediterránea y visitando seguidamente otras ciudades españolas y extranjeras (el Movimiento llevó su exhibición a Buenos Aires, Formosa, Caracas, Nueva York, etc.); paralelamente en las muestras se fueron integrando cada año nuevos artistas y grupos, como el Grupo Picasso de Málaga, el cual se encargó en 1962 de organizar en su ciudad la "V Muestra de Arte Actual del Mediterráneo». Los grupos, principalmente, fueron quienes se ocuparon de obtener los lugares 
de exposición y participar en la organización; por otro lado, a nivel teórico el Movimiento contó con críticos y creadores como Aguilera Cerni, Juan Eduardo Cirlot, Juan Pórtoles, Alexandre Cirici, Joan Josep Tharrats, Fuster, etc., quienes se ocuparon de destacar la importancia y proyección del arte mediterráneo en el contexto de la plástica ibérica e internacional.

Con todo ello se pretendía subrayar la importancia de un entorno y cultura especialmente identificado con el mar Mediterráneo, cuya larga e importantísima incidencia en el arte se prolonga con destacado vigor a lo largo de las décadas de esta segunda mitad de siglo hasta la actualidad, en la cual perdura esta mediterraneidad como una rica e irrenunciable tradición, que a la vez se ha convertido en un identificable e inmediato reto para la creación artística presente. 